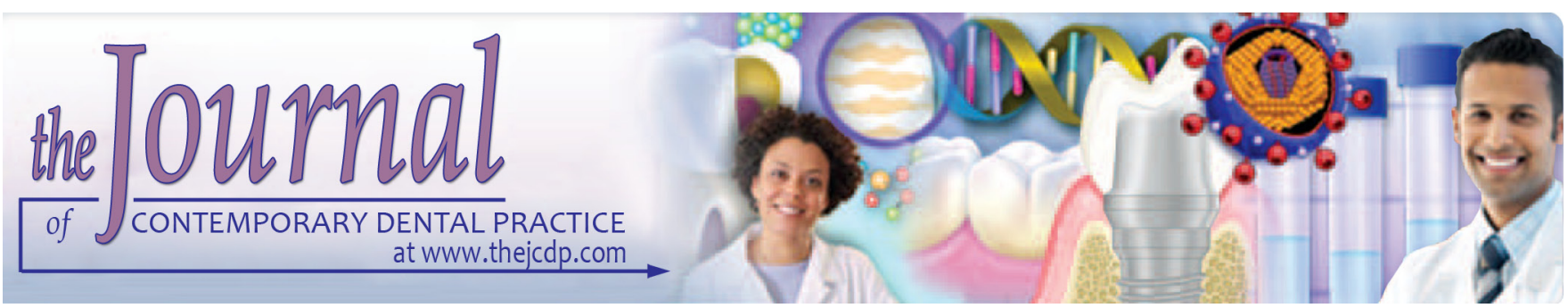

\title{
Effect of Different Thicknesses of Pressable Ceramic Veneers on Polymerization of Light-cured and Dual-cured Resin Cements
}

\author{
${ }^{1}$ Seok-Hwan Cho, ${ }^{2}$ Arnaldo Lopez, ${ }^{3}$ David W Berzins, ${ }^{4}$ Soni Prasad, ${ }^{5}$ Kwang Woo Ahn
}

\begin{abstract}
Aim: This study evaluated the effects of ceramic veneer thicknesses on the polymerization of two different resin cements.

Materials and methods: A total of 80 ceramic veneer disks were fabricated by using a pressable ceramic material (e.max Press; Ivoclar Vivadent) from a Low Translucency (LT) ingot (A1 shade). These disks were divided into light-cured (LC; NX3 Nexus LC; Kerr) and dual-cured (DC; NX3 Nexus DC; Kerr) and each group was further divided into four subgroups, based on ceramic disk thickness $(0.3,0.6,0.9$, and $1.2 \mathrm{~mm})$. The values of Vickers microhardness $(\mathrm{MH})$ and degree of conversion (DOC) were obtained for each specimen after a 24-hour storage period. Association between ceramic thickness, resin cement type, and light intensity readings $\left(\mathrm{mW} / \mathrm{cm}^{2}\right)$ with respect to microhardness and degree of conversion was statistically evaluated by using analysis of variance (ANOVA).
\end{abstract}

Results: For the DOC values, there was no significant difference observed among the LC resin cement subgroups, except in the $1.2 \mathrm{~mm}$ subgroup; only the DOC value $(14.0 \pm 7.4 \%)$ of $1.2 \mathrm{~mm}$ DC resin cement had significantly difference from that value $(28.9 \pm 7.5 \%)$ of $1.2 \mathrm{~mm} \mathrm{LC}$ resin cement $(p<0.05)$. For the $\mathrm{MH}$

\footnotetext{
${ }^{1,4}$ Department of General Dental Sciences, Marquette University School of Dentistry, Milwaukee, Wisconsin, USA

${ }^{2}$ Marquette University School of Dentistry, Milwaukee Wisconsin, USA

${ }^{3}$ Department of General Dental Sciences, Graduate Dental Biomaterials, Marquette University School of Dentistry Milwaukee, Wisconsin, USA

${ }^{5}$ Division of Biostatistics, Medical College of Wisconsin Milwaukee, Wisconsin, USA

Corresponding Author: Seok-Hwan Cho, Assistant Professor and Director, Department of General Dental Sciences Predoctoral Prosthodontics and Biomaterials, Marquette University School of Dentistry, 1801 W Wisconsin, Ave, 53233 Milwaukee, Wisconsin, USA, Phone: (414)288-5411, e-mail: seokhwan.cho@marquette.edu
}

values between LC and DC resin cement groups, there was statistically significant difference $(p<0.05)$; overall, the $\mathrm{MH}$ values of $L C$ resin cement groups demonstrated higher values than DC resin cement groups. On the other hands, among the $\mathrm{DC}$ resin cement subgroups, the $\mathrm{MH}$ values of $1.2 \mathrm{~mm} \mathrm{DC}$ subgroup was significantly lower than the $0.3 \mathrm{~mm}$ and $0.6 \mathrm{~mm}$ subgroups ( $p<0.05)$. However, among the LC subgroups, there was no statistically significant difference among them $(p>0.05)$.

Conclusion: The degree of conversion and hardness of the resin cement was unaffected with veneering thicknesses between 0.3 and $0.9 \mathrm{~mm}$. However, the $\mathrm{DC}$ resin cement group resulted in a significantly lower $\mathrm{DOC}$ and $\mathrm{MH}$ values for the $1.2 \mathrm{~mm}$ subgroup.

Clinical Significance: While clinically adequate polymerization of LC resin cement can be achieved with a maximum $1.2 \mathrm{~mm}$ of porcelain veneer restoration, the increase of curing time or light intensity is clinically needed for DC resin cements at the thickness of more than $0.9 \mathrm{~mm}$.

Keywords: Laboratory research, Resin cement, Thickness, Veneer.

How to cite this article: Cho S-H, Lopez A, Berzins DW, Prasad S, Ahn KW. Effect of Different Thicknesses of Pressable Ceramic Veneers on Polymerization of Lightcured and Dual-cured Resin Cements. J Contemp Dent Pract 2015;16(5):347-352.

\section{Source of support: Nil}

Conflict of interest: None

\section{INTRODUCTION}

The desire for improved esthetics has resulted in increased popularity and widespread use of ceramic restorations. ${ }^{1,2}$ Ceramic restorations, such as veneers, inlays, onlays, and, crowns, have shown increased longevity when cemented with resin cements. ${ }^{2}$ Resin cements have made a great impact on dentistry due to their esthetic shade-matching potential, improved flexural and compressive strengths, superior retention, and fracture resistance. ${ }^{2-4}$ 
There are three types of resin cements available to clinicians for cementing ceramic restorations. They are light-cured (LC), dual-cured (DC), and auto-cured resin cement. Unlike auto-cured resin cements, which are solely chemically-cured, LC and DC resin cements require adequate light for optimal polymerization..$^{5-10}$ Since the polymerization occurs through light activation, LC resin cements are directly affected by the thickness of the restoration. ${ }^{1,10}$ In contrast, DC resin cements start to polymerize once the base and catalyst are mixed. Although the amount of amine in the base is responsible for decreasing the setting time, DC resin cement is still slower in polymerization time than LC resin cements. ${ }^{11,12}$ Dual-cured resin cements are, therefore, able to compensate for inadequate light transmission and may be more efficient at polymerizing with increased ceramic thicknesses.

Adequate polymerization is crucial in determining the life of resin bonded ceramic restorations. Incomplete polymerization of resin cement can lead to color instability, toxicity from residual monomer, decreased bond strength and postoperative sensitivity, leading to increased risk of microleakage and caries. ${ }^{13-16}$

In order to evaluate proper polymerization of resin cement, hardness testing is commonly used as a simple and reliable method. ${ }^{17-25}$ Microhardness $(\mathrm{MH})$ is defined as the resistance of a material to indentation or penetration and has been used as a valid correlation with degree of polymerization, indicating that $\mathrm{MH}$ values increase as degree of polymerization increase. ${ }^{26,27}$ Another method used to evaluate polymerization is degree of conversion (DOC) by using infrared spectroscopy, also known as fourier transform infrared spectroscopy (FTIR). ${ }^{28-32}$ This DOC value in dental resin cements represents the percentage of aliphatic carbon double bonds $(\mathrm{C}=\mathrm{C})$ converted to single bonds $(\mathrm{C}=\mathrm{C})$.

The thickness of the ceramic restoration has an effect on the polymerization of the resin cement. ${ }^{33-36}$ For instance, Lee et $\mathrm{al}^{33}$ have shown that ceramic thickness had a profound effect on light transmission and curing efficiency, compared to the ceramic shade. However, most of the studies did not indicate the thickness of porcelain veneer restorations, because porcelain veneer thickness is approximately 0.3 to $0.9 \mathrm{~mm}$. Thus, the purpose of this study was to evaluate the effect of ceramic veneer thicknesses on the polymerization of two different resin cements, DC and LC. The hypothesis of the study was that there are no differences in $\mathrm{MH}$ and DOC between LC and DC resin cements.

\section{MATERIALS AND METHODS}

A total of 80 ceramic veneer disks (diameter, $7 \mathrm{~mm}$ ) were fabricated by using pressable ceramic material (e.max
Table 1: Resin cements used in study

\begin{tabular}{lllll}
\hline Resin & & & LOT & Resin \\
Cement & Manufacturer & Monomer & number & shade \\
\hline Nexus 3 & Kerr, Orange, & Bis-GMA and & 4691126 & White \\
LC & CA, USA & dimethacrylate & & \\
Nexus 3 & Kerr, Orange, & Bis-GMA and & 4711057 & White \\
DC & CA, USA & dimethacrylate & & \\
\hline
\end{tabular}

Press; Ivoclar Vivadent) from a low translucency (LT) ingot (A1 shade). These disks were divided into DC and LC groups (Table 1) and each group was divided into four subgroups, based on the ceramic disk thickness $(0.3,0.6$, 0.9 and $1.2 \mathrm{~mm}$ ). Table 2 shows the average thickness of each group. The light transmission value of each group of ceramic disks was measured with a hand-held LED radiometer (Demetron, Kerr) three times. In addition, an unobstructed light transmission value was recorded as the control. An average of the three readings were recorded as a light transmittance value (LTV) for each disk in $\mathrm{mW} / \mathrm{cm}^{2}$ (Table 3).

Mylar strips (Alsip, GC America Inc.) were placed individually on the upper surface of each sample to ensure an even and smooth surface. They also provided isolation from the ceramic disk. Each resin cement disk was fabricated by two different polymerization modes; light-cured and dual-cured. Each resin cement specimen was polymerized through each of the prepared ceramic veneer disks for 15 seconds with an LED curing light (Demi Plus LED; Kerr) (Fig. 1). Then, each resin cement sample was stored into individualized dry containers for 24 hours at room temperature. ${ }^{16,20,26,28,30,31,33}$ After a 24-hour storage period, the degree of conversion (DOC) was measured with a FTIR ATP spectroscopy device (Specac Silver Gate Evolution Single Reflection, Specac). Each specimen was placed on the surface of the zinc selenide pellet (Specac) in order to obtain the absorption spectra of the nonpolymerized and polymerized forms of the LC and DC resin cement specimens. A total of 64

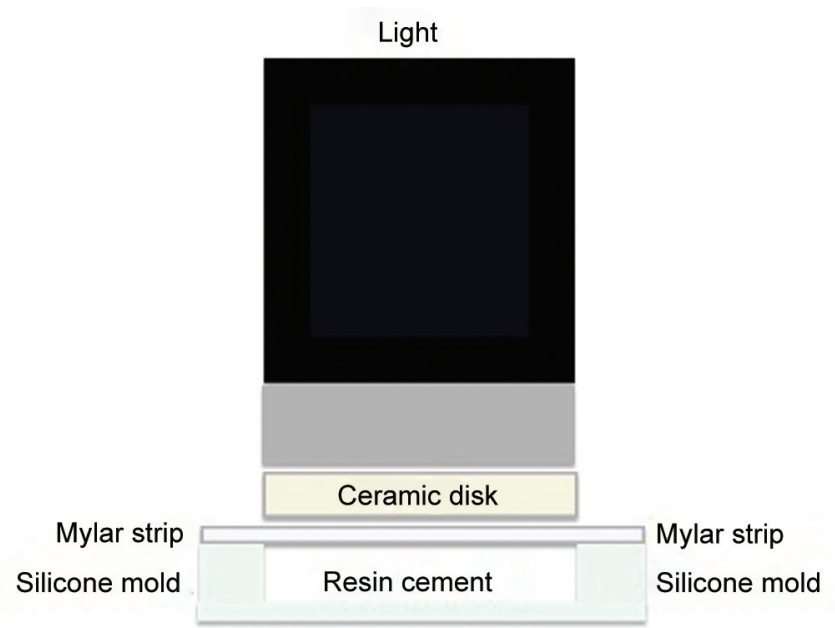

Fig. 1: Diagram of experimental setup 


\begin{tabular}{llllllll}
\hline \multicolumn{8}{c}{ Table 2: Average thickness (mm) of subgroups } \\
\hline LC.3 & LC.6 & LC.9 & LC1.2 & DC.3 & DC.6 & DC.9 & DC1.2 \\
\hline 0.301 & 0.616 & 0.945 & 1.199 & 0.308 & 0.598 & 0.963 & 1.197 \\
\hline
\end{tabular}

Table 3: Average light transmittance values $\left(\mathrm{mW} / \mathrm{cm}^{2}\right)$ for various thicknesses of pressable ceramic disks

\begin{tabular}{lllll}
\hline Control $(0 \mathrm{~mm})$ & $0.3 \mathrm{~mm}$ & $0.6 \mathrm{~mm}$ & $0.9 \mathrm{~mm}$ & $1.2 \mathrm{~mm}$ \\
\hline 900 & 585 & 566 & 558 & 549 \\
\hline
\end{tabular}

scans at $4 \mathrm{~cm}^{-1}$ were obtained from the region between 1500 and $1800 \mathrm{~cm}^{-1} \cdot 29,30$ Within this range, the aliphatic carbon double-bond $(\mathrm{C}=\mathrm{C})$ absorbance peak intensity (located at $1638 \mathrm{~cm}^{-1}$ ) and that of the aromatic component (located at $1608 \mathrm{~cm}^{-1}$; reference peak) were selected. Both of the peaks can be found in materials, which contain aromatic vinyl bonds of bisphenol and aliphatic bonds of the methacrylate functional group.

The following formula ${ }^{29,30}$ was then used to calculate the DOC of each individual resin cement specimen:

DOC $(\%)=100\left[1-\left({ }^{*} \mathrm{R}\right.\right.$ polymerized $/{ }^{*} \mathrm{R}$ nonpolymerized)]

${ }^{*} \mathrm{R}=$ the ratio between the absorbance peak at $1638 \mathrm{~cm}^{-1}$ and $1608 \mathrm{~cm}^{-1}$.

In addition, the values of $\mathrm{MH}$ were obtained by using Vickers MH tester (Kentron; Torsion Balance Co) at a $20 \times$ magnification. Three indentations were created on the upper surface of the resin cement disks, which is the surface closest to the light source under a $300 \mathrm{gm}$ load and 15 seconds of indentation time. In total, $240 \mathrm{MH}$ readings ( $3 \times 80$ specimens) were recorded. An average of the three $\mathrm{MH}$ values were calculated.

Two-way analysis of variance (ANOVA) models with interaction were used to compare DOC and $\mathrm{MH}$ of all four subgroups of DC and LC resin cement. The normality assumption was checked based on Kolmogorov-Smirnov test. Log transformation was performed for the $\mathrm{MH}$ data because the residuals of the two way ANOVA with their raw data did not satisfy the normality assumption. False discovery rate control was employed to adjust for multiple testing.

\section{RESULTS}

Table 4 lists the mean values and standard deviations of DOC (\%) for LC and DC resin cement groups. Both LC and DC groups showed a decrease in DOC with increased

Table 4: Degree of conversion (\%) with mean \pm standard deviation

\begin{tabular}{lllll}
\hline Thickness & $0.3 \mathrm{~mm}$ & $0.6 \mathrm{~mm}$ & $0.9 \mathrm{~mm}$ & $1.2 \mathrm{~mm}$ \\
\hline LC & $32.2 \pm 8.7^{\mathrm{a}}$ & $29.6 \pm 5.9^{\mathrm{a}}$ & $29.2 \pm 8.1^{\mathrm{a}}$ & $28.9 \pm 7.5^{\mathrm{a}}$ \\
DC & $34.8 \pm 12.8^{\mathrm{a}}$ & $32.7 \pm 6.4^{\mathrm{a}}$ & $28.5 \pm 8.8^{\mathrm{a}}$ & $14.0 \pm 7.4^{\mathrm{b}}$ \\
\hline
\end{tabular}

*Numbers with a differing lower case letter show a statistically significant difference according to the Kolmogorov-Smirnov test at $p<0.05$
Table 5: Microhardness $\left(\mathrm{kg} / \mathrm{mm}^{2}\right)$ with means \pm standard deviation

\begin{tabular}{lllll}
\hline Thickness & $0.3 \mathrm{~mm}$ & $0.6 \mathrm{~mm}$ & $0.9 \mathrm{~mm}$ & $1.2 \mathrm{~mm}$ \\
\hline LC & $31.1 \pm 8.0^{\mathrm{a}}$ & $30.7 \pm 5.8^{\mathrm{a}}$ & $29.1 \pm 3.8^{\mathrm{a}}$ & $28.1 \pm 3.7^{\mathrm{a}}$ \\
DC & $18.2 \pm 4.4^{\mathrm{b}}$ & $15.4 \pm 2.5^{\mathrm{b}}$ & $13.2 \pm 5.3^{\mathrm{b}, \mathrm{c}}$ & $9.6 \pm 1.8^{\mathrm{c}}$ \\
\hline
\end{tabular}

${ }^{*}$ Numbers with a differing lower case letter show a statistically significant difference according to the Kolmogorov-Smirnov test at $p<0.05$

ceramic thickness, indicating an increase in incomplete polymerization. Within the DC subgroups, the $1.2 \mathrm{~mm}$ DC resin cement subgroup showed significantly lower DOC when compared to $0.3,0.6$, and 0.9 mm subgroups $(\mathrm{p}<0.05)$. However, there was no significant difference observed among the LC resin cement subgroups: $0.3,0.6$, 0.9 and $1.2 \mathrm{~mm}$. In addition, there was no statistically significant difference between LC and DC resin cement groups, except in the $1.2 \mathrm{~mm}$ subgroup where the DOC value $(14.0 \pm 7.4 \%)$ of the $\mathrm{DC}$ resin cement was significantly lower than the value $(28.9 \pm 7.5 \%)$ of the LC resin cement $(\mathrm{p}<0.05)$.

Table 5 shows the mean values and standard deviations of MH for LC and DC resin cement groups. Between the LC and DC resin cement groups, there was a statistically significant difference in terms of $\mathrm{MH}$ $(\mathrm{p}<0.05)$; overall, the $\mathrm{MH}$ values of the LC resin cement groups demonstrated higher values than the DC resin cement groups. Within the DC resin cement subgroups, the $\mathrm{MH}$ values of the $1.2 \mathrm{~mm}$ subgroup were significantly lower than the values of the 0.3 and $0.6 \mathrm{~mm}$ subgroups $(\mathrm{p}<0.05)$. However, within the LC subgroups, there was no statistically significant difference among the ceramic disk thickness groups with respect to $\mathrm{MH}$.

\section{DISCUSSION}

This study evaluated the effect of different porcelain veneer thicknesses on the polymerization of two different resin cements, one DC and one $\mathrm{LC}$, by using the values of DOC (\%) and MH. Since porcelain veneer thickness is approximately 0.3 to $0.9 \mathrm{~mm}$, the result of this study can be clinically very important for veneer cementation procedures, compared with other studies which used very large thickness specimens of ceramics for resin cements. The hypothesis of this study was rejected because DC and LC resin cements showed significant difference in DOC for $1.2 \mathrm{~mm}$ and in $\mathrm{MH}$ for all porcelain veneer thicknesses.

A decreased DOC (\%) and $\mathrm{MH}$ for the DC resin group with an increase of ceramic thicknesses is consistent with other studies. ${ }^{20,33-36}$ Meng et $\mathrm{al}^{20,34}$ demonstrated that ceramic thickness had a significant effect on hardness of DC resin cements, especially when ceramic 
thickness was more than $4 \mathrm{~mm}$. They also mentioned that the autocure components of DC resin cements did not produce significant compensation with regard to mechanical properties when light curing is diminished with greater ceramic thicknesses, and that polymer structure of the DC resin cements mainly depended on the intensity of light irradiation. The autocuring mechanism of DC resin cement is thought to polymerize sites not reached by light transmission due to thick, dark shaded or opaque restorative materials. However, this autocuring component of DC resin has been described as slower or ineffective. ${ }^{21,35}$ In other words, although the DC resin cement was developed with the purpose of having both favorable characteristics of autocured and LC cements, these two modes of activation are not equivalent. El-Mowafy and Rudo ${ }^{35}$ mentioned that the autocuring component by itself was not enough to ensure high hardness of DC resin cement. If light transmission is not sufficient, the light activation mode of DC resin cement will be affected and complete polymerization will be compromised. ${ }^{8}$ In addition to ceramic thickness, the shade, optical translucency, and refraction index of porcelain restorations may influence the amount of light transmission. ${ }^{25,37}$ Soares et $\mathrm{al}^{25}$ showed that the effect of the ceramic restoration shade was less significant that the thickness when they compared among different shades (A1, A2, A3, A3 and A3.5) and different thicknesses (0, 1,2 and $4 \mathrm{~mm}$ ).

Since, the ceramic restoration absorbs, reflects and refracts the curing light, the amount of total energy from the light source reaching the cement should be considered in order to achieve adequate polymerization of resin cements. ${ }^{24,33,37,38}$ Lee et $\mathrm{al}^{33}$ demonstrated a marked decrease in light intensity with ceramic thicknesses over $1 \mathrm{~mm}$, from $700 \mathrm{~mW} / \mathrm{cm}^{2}$ to approximately $270 \mathrm{~mW} / \mathrm{cm}^{2}$. However, they showed that above $1 \mathrm{~mm}$ thickness, the decrease in light intensity was more gradual. However, the present study showed a gradual decrease in light intensity from the $0 \mathrm{~mm}$ (control) $\left(900 \mathrm{~mW} / \mathrm{cm}^{2}\right)$, the $0.3 \mathrm{~mm}$ ceramic thickness $\left(585 \mathrm{~mW} / \mathrm{cm}^{2}\right)$ to $1.2 \mathrm{~mm}$ thickness $\left(549 \mathrm{~mW} / \mathrm{cm}^{2}\right)$. This difference between the two studies may result from different ceramic materials, which could affect the light transmittance, or the light curing unit itself. With this light attenuation in mind, different recommendations have been made to compensate for it. Incorporation of longer curing periods and multidirectional curing was suggested to overcome the influence of ceramic thickness. ${ }^{24,33}$ Lee et $\mathrm{al}^{33}$ emphasized the increase in polymerization time because the polymerization time recommended by the manufacturers was not enough to compensate for attenuation of light by the restoration thicknesses; the time recommended by the manufacturers roughly corresponded to the times needed to achieve maximum hardness of cements directly exposed to light. In terms of type of light curing unit and light curing time relationship, there are conflicting accounts in the literature. ${ }^{37,38}$ Rasseto et $\mathrm{al}^{37}$ concluded that an adequate level of polymerization was achieved with a 40 seconds cure with a conventional halogen light for feldspathic and Empress veneers. However, a plasma arc curing light and a high intensity halogen light required 10 seconds and 15 seconds for adequate degree of polymerization. On the other hand, Hooshmand et $\mathrm{al}^{38}$ demonstrated that 20 seconds with a high-power LED light was not sufficient for the polymerization of DC resin cements covered with over $2 \mathrm{~mm}$ thickness of ceramic restorations. In the present study, a LED light source (Demi ${ }^{\text {plus}}$ ) was used, based on the manufacturer's recommended time (5 seconds). However, a greater light polymerization time ( 15 seconds) could have been used to account for the ceramic thickness and light attenuation.

In the present study, although DOC values did not show statistically significant difference between the LC and DC resin cement groups, there was statistically significant difference for the values of $\mathrm{MH}$ between the LC and DC resin cement groups. Since, the mechanical properties of resin cements are influenced by type and composition of the resin matrix, filler type, filler load and mode of polymerization, the absolute values of $\mathrm{MH}$ should not used for comparison with DOC values. ${ }^{20}$ The filler particles incorporated into the matrix provide higher values of strength than the matrix itself. Therefore, up to a certain limit, a higher filler load may be expected to improve mechanical properties. ${ }^{31,32}$ Pilo and Cardash ${ }^{16}$ demonstrated a correlation between volumetric filler content and hardness. The difference of $\mathrm{MH}$ values between the LC and DC resin cement groups in the present study can be explained by their differences in filler content; the LC resin cement (NX3 Nexus; Kerr) used in this study has $47.7 \%$ volumetric filler content, which is slightly higher than the $43.3 \%$ volumetric filler content of the DC resin cement. In contrast, Hoffman et $\mathrm{al}^{21}$ showed DC resin cement to have higher hardness values than $\mathrm{LC}$ cements.

The DC resin cement group showed adequate values of DOC and MH only up to $0.9 \mathrm{~mm}$ ceramic thickness. For this reason, this thickness $(0.9 \mathrm{~mm})$ can be considered to be the critical thickness for the DC resin cement group. Within the limitation of the study, above this critical thickness level, the DC resin cement showed significantly less sensitivity to the curing light. On the other hand, the LC resin cement group did not show statistically significant difference among the different thicknesses (0.3, 0.6, 0.9 and $1.2 \mathrm{~mm})$; it means the light activation 
was enough to polymerize the LC resin cements up to $1.2 \mathrm{~mm}$. While clinically adequate polymerization of LC resin cement can be achieved with a maximum $1.2 \mathrm{~mm}$ of veneer restoration, the increase of curing time or light intensity is clinically needed for DC resin cements at the thickness of more than $0.9 \mathrm{~mm}$.

There were certain limitations to the experimental design. In the present study, the dry storage of specimens does not accurately simulate intraoral condition. In addition, other clinical variables can affect the DOC and $\mathrm{MH}$ of resin cements; effect of different cement agents, curing methods, and ceramic shade should be taken into consideration. Further studies with various cement agents, shade and light curing methods will be indicated for comparison.

\section{CONCLUSION}

Within the limitation of the study, the degree of conversion and hardness of the LC and DC resin cements were not affected with veneering thicknesses between 0.3 and $0.9 \mathrm{~mm}$. However, the DC resin cement group resulted in a significantly lower DOC and MH values for the $1.2 \mathrm{~mm}$ subgroup.

\section{ACKNOWLEDGMENTS}

The authors would like to thank Dr Raymond Fournelle, Professor of Mechanical Engineering, for his collaborative efforts. This study was supported by a grant from the Marquette University School of Dentistry and by grant 1UL1RR031973 from the Clinical and Translational Science Award (CTSI) program of the National Center for Research Resources, National Institutes of Health.

\section{REFERENCES}

1. Blackman R, Barghi N, Duke E. Influence of ceramic thickness on the polymerization of light cured resin cement. J Prosthet Dent 1990 Mar;63(3):295-300.

2. Craig R, Powers J. Restorative dental materials. St Louis: Mosby 2002;11:p 251.

3. Gorman C, McDevitt W, Hill R. Comparison of two heatpressed all-ceramic dental materials. Dent Mater 2000 Nov;16(6):389-395.

4. Cattell M, Knowles J, Clarke R. The biaxial flexural strength of two pressable ceramic systems. J Dent 1999 Mar;27(3):183-196.

5. Koishi Y, Tanoue N, Atsuta M, Matsumura H. Influence of visible-light exposure on colour stability of current dualcurable luting composites. J Oral Rehabil 2002 Apr;29(4):387-393.

6. Tanoue N, Koishi Y, Atsuta M, Matsumura H. Properties of dual-curable luting composites polymerized with single and dual curing modes. J Oral Rehabil 2003 Oct;30(10):1015-1021.

7. Lee I, Um C. Thermal analysis on the cure speed of dual cured resin cements under porcelain inlays. J Oral Rehabil 2001 Feb;28(2):186-197.
8. Rueggeberg FA, Caughman WF. The influence of light exposure on polymerization of dual-cure resin cements. Oper Dent 11993 Mar-Apr;18(2):48-55.

9. Eliades G, Vougiouklakis G, Caputo A. Degree of double bond conversion in light-cured composites. Dent Mater 1987 Feb;3(1):19-25.

10. Leung R, Fan P, Johnston W. Post-irradiation polymerization of visible light-activated composite resin. J Dent Res 1983 Mar;62(3):363-365.

11. Suh B, Feng L, Pashley D, Tay F. Factors contributing to the incompatibility between simplified-step adhesives and chemically-cured or dual-cured composites. Part III. Effect of acidic resin monomers. J Adhes Dent 2003 Winter;5(4):267-282.

12. Caughman W, Caughman G, Shiflett R, Rueggeberg R, Schuster G. Correlation of cytotoxicity, filler loading and curing time of dental composites. Biomaterials 1991 Oct;12(8):737-740.

13. Pires J, Cvitko E, Denehy G, Swift Jr E. Effects of curing tip distance on light intensity and composite resin microhardness. Quintessence Int 1993 Jul;24(7):517-521.

14. Janda R, Roulet J, Kamisky M, Steffin G, Latta M. Color stability of resin matrix restorative materials as a function of the method of light activation. Eur J Oral Sci 2004 Jun;112(3):280-285.

15. Goldberg M. In vitro and in vivo studies on the toxicity of dental resin components: a review. Clin Oral Investig 2008 Mar;12(1):1-8.

16. Pilo R, Cardash H. Post-irradiation polymerization of different anterior and posterior visible light-activated resin composites. Dental Mater 1992 Sep;8(5):299-304.

17. Cekic-Nagas I, Ergun G. Effect of different light curing methods on mechanical and physical properties of resincements polymerized through ceramic discs. J Appl Oral Sci 2011 Aug;19(4):403-412.

18. Aguiar F, Braceiro A, Ambrosano G, Lovadino J. Hardness and diametral tensile strength of a hybrid composite resin polymerized with different modes and immersed in ethanol or distilled water media. Dent Mater 2005 Dec;21(12):10981103.

19. Chang H, Kim J. Early hardness and shear bond strength of dual cure resin cement light cured through resin overlays with different dentin layer thicknesses. Oper Dent 2014 JulAug;39(4):398-406.

20. Meng X, Yoshida K, Atsuta M. Hardness development of dual-cured resin cements through different thicknesses of ceramics. Dent Mater J 2006 Mar;25(1):132-137.

21. Hoffman N, Papsthart G, Hugo B, Klaiber B. Comparison of photo-activation versus chemical or dual-curing of resinbased luting cements regarding flexural strength, modulus and surface hardness. J Oral Rehabil 2001 Nov;28(11): 1022-1028.

22. Hasegawa E, Boyer D, Chan D. Hardening of dual-cured cements under composite resin inlays. J Prosthet Dent 1991 Aug;66(2):187-192.

23. Braga R, Cesar P, Gonzaga C. Mechanical properties of resin cements with different activation modes. J Oral Rehabil 2002 Mar;29(3):257-262.

24. Amato PA, Martins RP, dos Santos Cruz CA, Capella MV, Martins LP. Time reduction of light curing: Influence on conversion degree and microhardness of orthodontic composites. Am J Orthod Dentofacial Orthop 2014 Jul;146(1):40-46. 
25. Soares CJ, da Silva NR, Fonseca RB. Influence of the feldspathic ceramic thickness and shade on the microhardness of dual resin cement. Oper Dent 2006 May-Jun;31(3):384-389.

26. Ferracane JL. Correlation between hardness and degree of conversion during the setting reaction of unfilled dental restorative resins. Dent Mater 1985 Feb;1(1):11-14.

27. Rueggeberg FA, Craig RG. Correlation of parameters used to estimate monomer conversion in a light-cured composite. J Dent Res 1988 Jun;67(6):932-937.

28. Kim M, Kim K, Kim Y, Kwon T. Degree of conversion of two dual-cured resin cements light-irradiated through zirconia ceramic disks. J Adv Prosthodont 2013 Nov;5(4):464-470.

29. Souza E, Borges B, Oliveira D, Brandt W, Hirata R, Silva E, Sinhoreti $\mathrm{M}$. Influence of the curing mode on the degree of conversion of a dual-cured self-adhesive resin luting cement beneath ceramic. Acta Odontol Scand 2013 MayJul;71(3-4):444-448.

30. Rueggeberg F, Hashinger D, Fairhurst C. Calibration of FTIR conversion analysis of contemporary dental resin composites. Dent Mater 1990 Oct;6(4):241-249.

31. Di Francescantonio M, Aguiar T, Arrais C, Cavalcanti A, Davanzo C, Giannini M. Influence of viscosity and curing mode on degree of conversion of dual-cured resin cements. Eur J Dent 2013 Jan;7(1):81-85.

32. Tezvergil-Mutluay A, Lassila L, Vallittu P. Degree of conversion of dual-cure luting resins light-polymerized through various materials. Acta OdontolScand 2007 Aug;65(4): 201-205.

33. Lee JW, Cha HS, Lee JH. Curing efficiency of various resin-based materials polymerized through different ceramic thicknesses and curing time. J Adv Prosthodont 2011 Sep;3(3):126-231.

34. Meng X, Yoshida K, Atsuta M. Influence of ceramic thickness on mechanical properties and polymer structure of dual-cured resin luting agents. Dent Mater 2008 May;24(5): 594-599.

35. El-Mowafy O, Rubo M. Influence of composite inlay/onlay thickness on hardening of dual-cured resin luting agents. J Can Dent Assoc 2000 Mar;66(3):147.

36. Kilinc E, Antonson S, Hardigan P, Kesercioglu A. The effect of ceramic restoration shade and thickness on the polymerization of light- and dual-cure resin cements. Oper Dent 2011 Nov-Dec;36(6):661-669.

37. Rasetto FH, Driscoll CF, von Fraunhofer JA. Effect of light source and time on the polymerization of resin cement through ceramic veneers. J Prosthodont 2001 Sep;10(3): 133-139.

38. Hooshmand T, Mahmoodi N, Keshvad A. Microhardness of a resin cement polymerized by light-emitting diode and halogen lights through ceramic. J Prosthodont 2009 Jul;18(5):411-416. 